\title{
The Research on Class Construction in Universities Based on System Theory
}

\author{
Chen Rui, Wang Jing, Long Wei* \\ School of Economics and Management, Yunnan Agricultural University \\ Kunming, Yunnan 650201
}

\begin{abstract}
Based on system theory, this paper analyzes the elements of the "system" of university class" construction, and proposes that the construction principles of integrity, order, and dynamics. Furthermore, this paper puts forward that universities should pay attention to the influence of the external environment on university students, strengthen the construction of campus culture so that we can strengthen the ideological guidance of university students; we must deal with the relationship between the whole and the part, and pay attention to the growth of every student; and the class teachers should integrate into the class and influence the students.
\end{abstract}

Keywords-System theory; University class construction; Campus culture

\section{INTRODUCTION}

In many countries, especially the United States, universities have no classes like China. The "class" of American universities is based on schools. All students who enter the university in the same year are a "class", which is similar to the Chinese grade.

In China, classes are the basic organizational form of universities. After entering the universities, university students set up different classes according to different majors. The class management generally adopts the management mode of "university-----school---- department----major----class", and the class becomes the basic link of university student management. Class construction has become the main starting point to strengthen student management and the construction of classes not only directly affects the personal development of students, but also affects the talent training of universities. Nowadays, "95" has gradually become the main body in university, and "00" also become the freshman in university. The group of university students who grew up with computers and networks are relatively more innovative and willing to accept new things. Students no longer bind themselves to the class, but are more willing to interact with "Similar people" who share their interests. After entering university, students choose to join the student union, the youth volunteer association, and various community organizations to improve their abilities. They gain the Second Class Credits and at the same time find self-worth in the process of interacting with students of different majors. ${ }^{1}$ They are more willing to form a circle of interpersonal communication through the media through Weibo, WeChat and

\footnotetext{
1. Wang Huihui, Li Weisi. Research on Class Construction Management in Colleges and Universities under the New Situation [J]. Education

Modernization ,2018,5(38):191-193

2 Padulo (L.), Arbib (M.A.), System Theory [M]. Beijing science press, 1986:88-89

3 Wei Hongsen, Zeng Guopin, System Theory, Philosophy of system science [M].
}

QQ. Faced with this situation, how can universities do a good job in class construction in the system work of " establishing morality and cultivating qualified builders " is worthwhile to study.

The term system, originally derived from ancient Greek, means a whole made up of parts.. Today, due to different research perspectives, the concept definition of the system is also different. For example, "a system is a given set of elements and their normal behavior", "a system is an organized and an organized whole", "a system is a collection of related substances and processes", and so on. ${ }^{2}$ It is generally believed that a system is an organic whole with certain functions composed of several elements connected in a certain structure. ${ }^{3}$ The system method is to put the object of knowledge and practice into the system to investigate. To be specific, it is a method to comprehensively and accurately inspect the object from the perspective of the system, from the interaction and interaction between the system and the elements, elements and the environment, so as to achieve the optimization goal. 1937, American Austria biologist Von Bertalanffy first proposed the concept of system, which was widely concerned by the scientific community at that time. Later, some natural scientists, social scientists and philosophers joined the research activity and formed the system. The general trend of method research, many research results are continuously applied in people's practice, and gradually deepened in practice, so that system theory is continuously enriched and developed. ${ }^{4}$

According to the system theory, a system is defined as "an organized whole made up of components that interact in a way distinct from their interaction with other entities and which endures over some period of time". The system depends not only on the existence of various elements, but also the whole system. Von Bertalanffy mentioned that an organism conception in biology that emphasized consideration of the organism as a whole or a system. Therefore, in the view of system theory, the key to the system is to achieve $1=1>2$, that is, the total is greater than the sum of its elements. At the same time, Von Bertalanffy point out that a system grows through an exchange of energy between the system and its environment. ${ }^{5}$

The university is a system and the class also is a system. Class is the basic element of the university system, which is influenced by the external environment. Outside university,

\footnotetext{
Beijing: Tsinghua university press, 1995:161

${ }^{4}$ Fan Lin. Principles of system theory in class management [J]. Chinese Business, 2010(8):255-257

${ }^{5}$ Von Bertalanffy, Perspectives on General System Theory [M]. Edgar Taschdjian. George Braziller, New York 1974:15
} 
national politics, economy, culture and the development of science and technology are macro external environment of class system. Inside university, the Student Affairs Office, the Youth League Committee, the Academic Affairs Office, the Security Office and the Logistics Management Department constitute the micro-external environment for class. For the small system of class, class counselors, class committees and students are the constituent elements. These elements work together and interact to form a system of class construction. In particular, according to the "people-oriented" education concept advocated by modern education, students are the main body of the formulation and implementation of class rules and regulations, and are the main body of class competition activities, class committee elections and services also. In other words, all kinds of activities, students should respect the subjectivity, so that students can actively participate in the class construction as the "master". The ultimate goal of class construction is to help students to grow smoothly. Therefore, the design of many elements in the system must conform to the actual characteristics of the student, and should be carried out according to the characteristics of new generation who born after

1995 or even 2000.

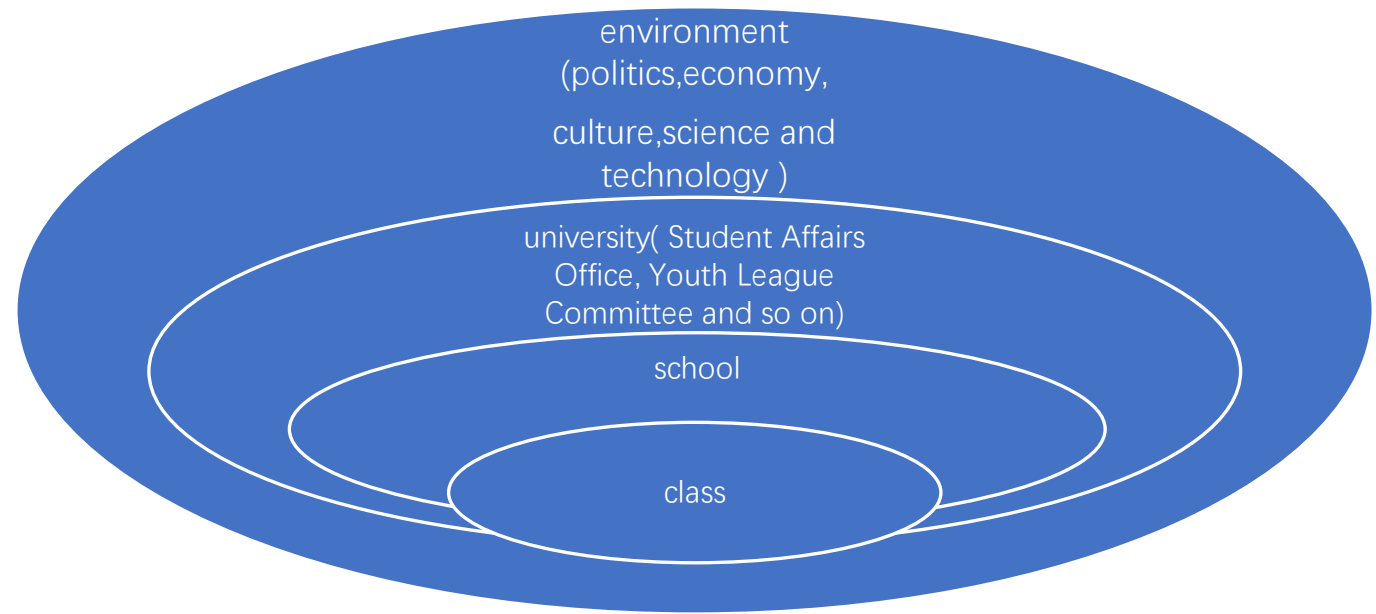

Fig. 1 Diagram of class system in Chinese university

According to the system theory, it is necessary to put all the elements of class construction into the system connection to coordinate and implement the whole. In practice, we should follow the principles of integrity, order and optimization.

\section{INTEGRITY PRINCIPLE}

First, the system responds to exogenous as a whole. Secondly, as a whole, the system has the properties and functions of each element. The system is not a mechanical addition of the elements, but an organic combination of them. Von Bertalanffy point out that the elements in the system do not exist in isolation, and the elements are interrelated, forming an integral whole. And Bertalanffy said, any system is an organic whole, which is not a mechanical combination or simple addition of the parts. The overall function of the system is the property that the elements do not have in an isolated state. ${ }^{6}$ Karl Marx said "the total product provided by 12 people in a 144hour working day is much more than that provided by 12 single laborers working 12 hours a day or 12 consecutive days. ${ }^{7}$ Von Bertalanffy against the view that the performance of elements is good, the overall performance must be good. If elements are separated from the whole system, they will lose their effect. In the construction of the class, management can influence the overall construction of the class no matter which element it starts with. Proper construction measures will have a positive effect

\footnotetext{
${ }^{6}$ Von Bertalanffy (L.). Basis, development and application of general system theory [M]. Social sciences academic press, 1988:90-91

7 Dai Dazhu. Socialist administration. [M]. Wuhan: central China normal university
}

on class construction; improper construction measures will have a negative effect on class construction. This means that sometimes the system function is greater than the sum of the individual elements, but if designed not properly, it may cause the system function to be less than the sum of the individual elements. Class construction needs to be considered as a whole, from the overall situation, the overall point of view, do not talk about work on a one-sided approach; it should not only clarify the responsibilities and division of labor of all departments and personnel, but also have the spirit of unity and cooperation.

\section{ORDER PRINCIPLE}

System theory believes that each system is composed of several subsystems, and the subsystem is composed of a certain number of lower-level elements. The internal structure of the system has hierarchical organizational features. This is because when the system is in a disordered state and the structure is unreasonable, the overall function will be less than the sum of the parts. This is the reason why we say "three monks have no water to eat" every day. To make the system as a whole greater than (in essence, is "better") the sum of parts, depends on the degree of order within the system, the degree of order, the more reasonable structure, will get the best system effect. ${ }^{8}$ Therefore, system theory requires in the class construction, to seriously summarize the class construction of the basic elements is what?

press.1995:35

${ }^{8}$ Fan Lin. Principles of system theory in class management [J]. Chinese Business, 2010(8):255-257 
And it is necessary to find the basic laws and functions of the class system, promote the elements of the class system from disorder to order, maximize the function of the basic elements, to achieve the minimum investment, the fastest speed, to achieve the function, so as to provide a solid foundation for class construction.

\section{DYNAMIC PRINCIPLE}

The dynamic nature of the system means that the organic relevance of the system is not static, but evolves over time. ${ }^{9}$ From the perspective of system theory, the system itself and the internal elements of the system are in the process of constant movement and change, and are dynamic. System science believes that any system has a process of organization, whether it is the system as a whole and elements, structure and function, feedback and regulation, hierarchy and level, system and environment, etc., all have dynamic nature. ${ }^{10}$ Do not think of a system as an absolutely closed, fixed system. As Engels pointed out, "interaction is the real ultimate cause of things. ${ }^{11}$ In a word, the dynamic principle is to grasp the development from the connection and further reveal the internal connection of the system from the development. ${ }^{12} \mathrm{~A}$ system always is one that receives input from the environment and/or releases output to the environment and system are the dynamic interaction of its components. Class construction as a system is also the same, it is moving and changing, its elements are subject to continuous development and change under the influence of subjective and objective environment, and the class system is in the process of constant change.

\section{CONCLUSION}

\section{A. Pay attention to the influence of external environment on class construction}

As mentioned above, according to the system theory, universities are also a subsystem of society, which will be affected by the environment. Therefore, class construction in universities is also affected by the external environment, that is, the social environment is also affect the class construction. Although these effects are macroscopic, they have an indirect impact on the class. Especially in the information age, the rapid development of information dissemination methods and dissemination speed, the impact of external macro-environment on university students and the impact on class construction can not be underestimated.

Many of the information in the mass media (especially the internet) affects the outlook on life of undergraduate. The rapid development of China's economy and the construction of market economy have made the market concept and competition consciousness of undergraduate continue to strengthen. These factors have an important impact on the thinking and behavior of students, which also affects the construction of classes in university.

Based on this, the premise of class construction is the construction of campus culture, and it is necessary to realize the

\footnotetext{
${ }^{9}$ Luo Liangzheng, Zhang Ying, Systematic Analysis of College Student Affairs Management[J], Jiangxi Education, 2006 (11): 35-37

${ }^{10}$ Hao Zhikang, Application of system theory in university affairs management [D].

Wuhan: Wuhan University of Science and Technology,2010
}

guidance of undergraduate' outlook on life through the "small environment" of the campus. Centering on "Education is the foundation, moral education is the first", university should construct scientific and rational ideas and frameworks in class activities, rules, regulations, and campus culture. University should give full play to the coordination of system elements such as the Student Affairs Office, the Youth League Committee, the Academic Affairs Office, the Security Office, the Logistics Management Department and Mental Health Education Center, and through organizing a variety of campus activities, build a campus culture platform containing ideals, teamwork, charity, and innovation, create a spiritual culture atmosphere, spread the core of socialism Values. Through the campus culture, lead the undergraduate to establish their lofty ideals, cultivate noble sentiments, and master professional knowledge. With a good "small environment" of campus culture, class construction has a foundation, enhance class cohesion, and build class culture.

\section{$B$. Handle the relationship between the part and the whole}

It is necessary to handle the overall and local relationship of the class management system. The class system is composed of various elements (members) related to it. While grasping the integrity of the class system, all students need to grow well. Only when all the students have grown up, the class system is considered successful. At the university, some problems may be just the problems of individual, but it will affect the achievement of the overall goals of the class. For example, there are very few students in the class who have absenteeism because of their own reasons. This is a partial problem, but it will affect the overall achievement of the class. For example, when the class is evaluated, it will be disqualified from participating in the class due to high class absenteeism. Therefore, in the construction of the class, we must pay attention to the performance of individual, and do not miss any students. It is like processing a product. If there is a problem in which part of the production, although it seems to be only an individual or partial problem, but for the consumer, the product is unqualified, which will directly affect the entire company brand and affects the realization of the company's goals.

\section{The class teachers must be integrated into the class construction}

As mentioned above, in accordance with the "peopleoriented" educational philosophy advocated by modern education, the past concepts and practices of "teachers are in charge of students and students are managed by teachers" must be changed. The class teacher and the students are the elements of the class system. They are the masters of the class and interact and influence each other. In other words, in class construction, the class teacher and the student are a whole, and they should not be separated. From the practice of class construction, we can also summarize such a rule. If the class teacher separates himself from the class, he does not often contact the students, does not communicate with the students constantly, does not hold class meetings regularly, does not go to the student dormitory frequently, and hope that students do not disturb himself, then

\footnotetext{
11 Selections of Marx and Engels (3). Beijing: People's publishing press.1972:552. 12 Fan Lin. Principles of system theory in class management [J]. Chinese Business, 2010(8):255-257
} 
basically this class teacher can not do a good job in class construction. At the same time, some teachers think that class construction is difficult, and their own ideas and requirements are difficult to implement in class. The reason is precisely because the class teachers do not integrate themselves into the class, do not really see themselves as a member of the class. The class teacher should go deep into students, conduct targeted investigation and analysis, and think more from the perspective of students. We should be good at observing and discovering practical problems that undergraduate encounter in their study and life, help them solve problems according to school rules and regulations, and satisfy students' reasonable demands to the maximum extent.

\section{ACKNOWLEDGMENT}

About the author:

1. Chen Rui (1973-) Female, School of Economics and Management, Yunnan Agricultural University, Associate Professor

Research Direction: Agricultural Economic Management

2. Long Wei (1974-) Female, School of Economics and Management, Yunnan Agricultural University, lecturer

Research direction: Agricultural Product Marketing

3.Wang Jing (1973-) Female, School of Economics and Management, Yunnan Agricultural University, lecturer

Research direction: Agricultural Product Marketing

\section{REFERENCES}

[1] Dai Dazhu. Socialist administration. [M]. Wuhan: central China normal university press.1995:35. (In Chinese)

[2] Fan Lin. Principles of system theory in class management [J]. Chinese Business, 2010(8):255-257. (In Chinese)

[3] Hao Zhikang, Application of system theory in university affairs management[D]. Wuhan: Wuhan University of Science and Technology,2010. (In Chinese)

[4] Luo Liangzheng, Zhang Ying, Systematic Analysis of College Student Affairs Management[J], Jiangxi Education, 2006 (11): 35-37. (In Chinese)

[5] Padulo (L.), Arbib (M.A.), System Theory [M]. Beijing science press, 1986:88-89. (In Chinese)

[6] Selections of Marx and Engels (3). Beijing: People's publishing press.1972:552. (In Chinese)

[7] Von Bertalanffy, Perspectives on General System Theory [M]. Edgar Taschdjian. George Braziller, New York 1974:15

[8] Von Bertalanffy (L.). Basis, development and application of general system theory [M]. Social sciences academic press, 1988:90-91. (In Chinese)

[9] Wang Huihui, Li Weisi. Research on Class Construction Management in Colleges and Universities under the New Situation [J]. Education Modernization ,2018,5(38):191-193. (In Chinese)

[10] Wei Hongsen, Zeng Guopin, System Theory, Philosophy of system science [M]. Beijing: Tsinghua university press, 1995:161. (In Chinese) 